
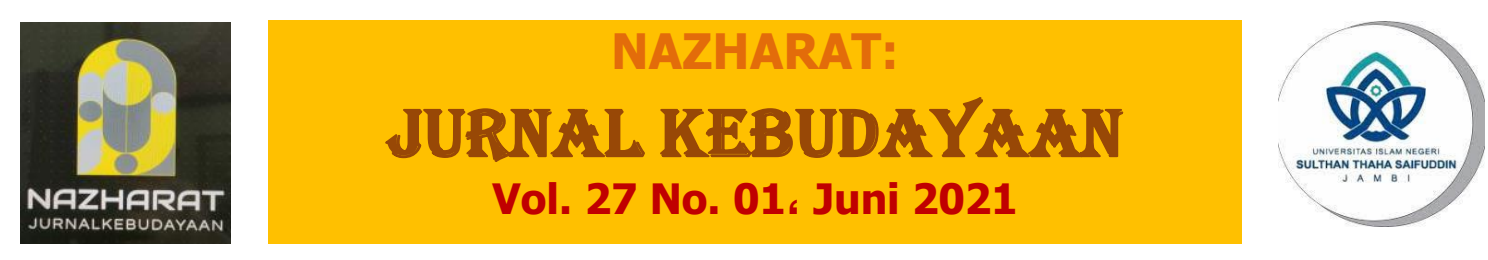

\title{
THE IDIOMATIC EXPRESSIONS USED BY THE CHARACTERS AS FOUND IN MEGAMIND MOVIE
}

\author{
Bielqis Elfath, Diana Rozelin, Ulfatmi Azlan \\ State Islamic University Sultan Thaha Saifuddin Jambi \\ bielqiselfath@gmail.com
}

The researcher discussed about The Idiomatic Expressions Used by The Characters as Found in Megamind movie. The movie has theme of heroic stories, in the dialogue it is found that the contain of idiomatic expressions, the movie storyline was good, has a good language structure and the movie contain the message that "anyone can be a hero". The purpose of this study is to determine the types of idiomatic expressions, the meaning of idiomatic expressions, and the types of idiomatic expressions that are the most dominant in used by characters such as those found in the Megamind movie. The theory used was Adam Makkai theory to look for types of idiomatic expressions, and the theory of Abdul Chaer to look for the meaning of idiomatic expressions. Characters are people which are represented in a dramatic or narrative work. Idioms are complex expressions whose meaning does not logically follow the individual meanings of their constituents. Idioms are divided into 2 parts, namely idioms of encoding and idioms of decoding. Idioms of decoding are divided into 2 , namely sememic idioms and lexemic idioms. Lexemic Idioms are divided into 5 types, namely phrasal verbs idioms, tournure idioms, irreversible binomial idioms, phrasal compound idioms, and incorporating idioms verbs. This research is qualitative research and used descriptive method. Based on the formulation of the problem, this study has revealed three findings. Consists of; First, there are 175 idiomatic types found, contained in 3 character characters in the Megamind movie which are divided into 5 types, namely, phrasal verb idioms found 54 idioms, tournure idioms found 5 idioms, irreversible binomial idioms there is no found idioms that used by each character in Megamind movie, phrasal compound idiom found 93 idioms and incorporating verbs idiom found 23 idioms. Second, there are 9 types of idiomatic meanings used by the characters in the Megamind movie, 3 lexical meanings, 4 contextual meanings, 4 grammatical meanings, 8 conceptual meanings found, 44 associative meanings found, 35 referential meanings found, 2 non-referential meanings were found,

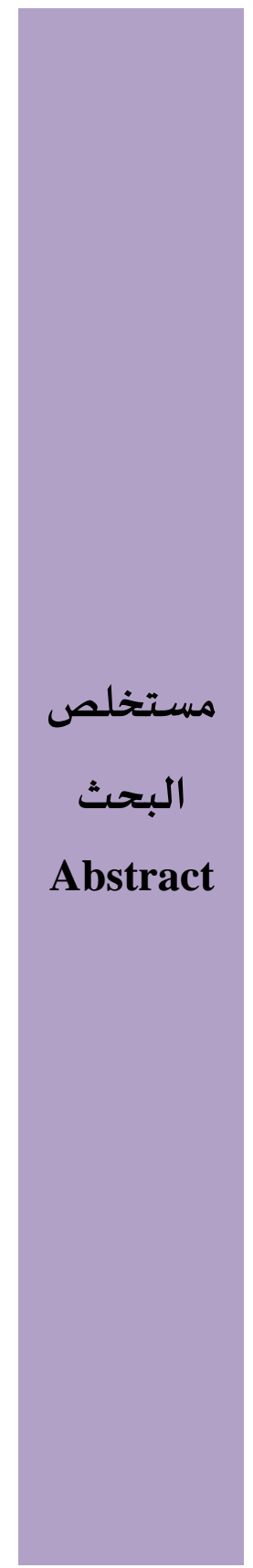


33 denotative meanings, and 42 connotative meanings. Third, the most dominant types of idiomatic expressions used are in the main character in the movie, namely the Megamind character totaling 63 types of Phrasal Compound Idioms and as many as 33 types of Phrasal Verb Idioms.

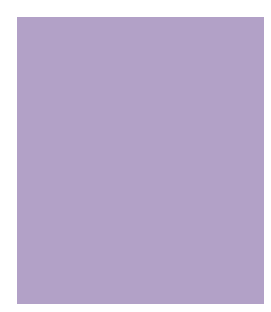

Keywords : The Idiomatic Expressions, Idiomatic Meaning, Megamind Movie

أسـاسية

Keyword

\section{INTRODUCTION (مقدمة)}

A human cannot live alone because they are social creatures who always communicate and share thoughts, ideas, opinions, and all kinds of other information with each other, both physically and verbally. To be able to communicate verbally human needs a "tool", which is called language.

Language is the human way to communicate with each other in communication to express their thought, idea, suggestion, emotion, and so on. Language has an important role in daily life. Without language, people may not be able to carry out their life. Even disabled people such as deaf people still have their language for communication, it is a sign language. Which means humans to be able to communicate with others.

In daily life, people should have abilities of reading and listening to receive information, speaking and, writing to give information. Knowing a language means knowing the morphemes, simple words, compound words, and their meanings. Not only that, there are fixed phrases, consisting of more than one words, with meanings that cannot be inferred by knowing the meanings of the individual words, such as idiomatic expressions.

Idioms are used in many ways in language, including through movies where speakers must convey messages which can only be spoken with idiomatic expression. It is very interesting to study different types of idioms that were used by a group of society and categorizing the idioms into many groups. English has idiomatic expressions which 
English speakers used to express their feeling and conditions using idiomatic expressions.

An idiom is an expression that cannot be understood if we try to analyze the meaning of each word in isolation because its meaning is different from its logic. Baker (1992:63) said that an idiom is defined as frozen patterns of language that allow little or no variation in form and often carry the meanings which cannot be decided from their components. It means that idiom cannot be translated literally from one language into another language without some changes in connotation. While according to Chaer (2007:296), idioms are units of language whether in the form of words, phrases, or sentences whose meanings cannot be drawn from the general grammatical rules prevailing in the language or cannot be predicted from the lexical meaning of the elements that make up them.

In this research, the movie becomes an object of the study. The movie is one of the literary works which people often watch to entertain and gain information. As with books or other printed works, the movie is a conductor of information to society. The information presented in a movie providing new knowledge to society. Whatever the genre of the theme, the movie always leaves a moral message to people that can absorb easily.

Besides, understanding a movie can be easier than reading a written text like a book. Based on this reason, the movie is strategically used as a communication tool for many people. Many of the English idioms that a person may hear spoken in America came from the movies. In watching a movie, a lot of people hardly understand the meaning of the idioms, because the meaning of the idioms is unpredictable from the grammatical rule. Moreover, the aim of the idioms in the movie can be accomplished only because words have a certain meaning.

Presently the production of the movie is dominated by the United States and even from the beginning until now. Since American movies are made in English, large numbers of globally popular movies are subsequently in English. Although the movies are produced in a foreign language, Indonesians enjoy English movie it has been evident that their enjoyment continues to increase. This is shown by their positive response toward English language movies which are popular in movie theatres, television 
broadcasts, and as recordings for home viewing circulated through various media in Indonesia.

One of the most successful Hollywood movies to have earned millions of dollars globally is the Megamind movie. The Megamind movie by The Dream Works Animation 3-D continues the action of attracting viewers in the second week of its screening Megamind managed to reap almost US \$ 90 million and was at the top of the list of best-selling movies. This thesis proposal focused on "The idiomatic expressions used by the characters as found in Megamind movie".

Because of that, the researcher chooses this title for the thesis studied as a material because the idiomatic expression is one of figurative language that the meaning difficult to understand for the common viewers. Also, the researcher often found movies containing idiomatic expressions in their dialog, so the researcher was interested in describes the types of idiomatic expressions and the meaning of the idiomatic expressions in this movie.

Moreover, the researcher chooses this movie because the storyline was good, acceptable to all ages, the message can be received with good viewers, have a good language structure, and this movie like the heroic themed stories in general, this movie also has two opposing characters, namely hero and villain who act as Megamind and Metroman, but in contrast to the general description of the heroic-themed story, this movie offers something new and fresh in accordance to its tagline which reads "superhero movie will never be the same".

Heroes who are idolized are not always heroes and instead, villain hated characters end up being heroes. This movie displays the message that "anyone can be a hero". This hero-themed movie shows something new and different, and also this movie gives quite a lot of idiomatic expressions. So, based on the reason above, the writer analyzed this movie and takes a title for research "The idiomatic expressions used by the characters as found in Megamind movie".

\section{THEORETICAL FRAMEWORK}

\section{Idiomatic Expression}

Idioms are words whose meaning cannot be seen either in lexical or grammatical and the meaning of idiom did not follow the form of the meaning of the individual 
words of which it is composed. One of the most important aspects of language is idioms. Idiomatic expressions are daily expressions that are used by English speakers.

They are frequently used in a wide variety of situations, from friendly conversations to more formal conversations and written contexts. Every language in the world has its idiom. In English itself, idioms play an important role in everyday life. People often hear idioms every day in a daily conversation, on television, radio, in a magazine, newspaper, etc. Instead of creating a new word, people use the words that already exist and unit them in a new meaning.

The idiomatic expressions are accepted as common usage in everyday speech and writing. While idioms are colorful expressions, people do not understand and neglect them. Less knowledge of idioms will make a language awkward and stilled in usage. In vocabulary studies, idioms have been approached from different perspectives.

After reading some materials and references, the researcher knows that there are some theories of an idiom that were proposed by some linguists. Here, the researcher presents some perspectives to reach an agreement on the definition of an idiom. Keraf (1984:109) said that idioms are structural patterns that deviate from general language rules (usually in the form of phrases) whose meaning is not the same as the combined meaning of the words that form it. According to Mantyla (2004:67), an idiom is an expression that contains more than one word, and whose meaning is different from the sum of the literal meanings of its components. Besides that, an idiom is a complex expressions whose meaning does not logically follow from the individual meanings of its constituents.

Based on all definitions of idiom above, the writer concludes that idiom is an expression, a word, phrase, or sentence whose meanings cannot be understood by individual words but must be learned as a whole. Although there is the various definition of idiomatic expressions, all of them share common features. The researcher could say that idiomatic expressions are different from the actual literal meaning. One of example idiomatic expressions is the idiom "watch out!" in a sentence "No.. No.. Slow it down, and stop. I said slow down. Hey watch out!". "watch out!” does not have a meaning that watching outdoors. The literal meaning is "to be careful, to pay attention, or on the alert and it is usually because the danger is imminent". 


\section{Types of Idiomatic Expression}

Idioms have been categorized by many scholars with different classes. For this study, the researcher chooses a theory proposed by Adam Makkai, in his book entitled Idiom Structure in English. Hinkel (2017:89) said it divide into two types. Those are: Idioms of encoding are those idiosyncratic lexical combinations that have transparent meanings involving collocational preferences and restrictions. Example: answer the door, wide awake, and blow one's nose.

Idioms of decoding refer to those non-identifiable and misleading lexical expressions whose interpretations could not be comprehended based on only learned linguistic conventions. In other words, the meaning of decoding idioms is unpredictable. Example: kick the bucket, pull's someone's leg, and beat about the bush

Makkai also classifies the idiom of decoding into two types. Those are lexemic idioms and sememic idioms. In this research, the researcher used lexemic idioms than sememic idioms. The lexemic idioms are divided into five types.

A phrasal verbs idiom is a compound verb consisting of a verb and a particle (adverb or preposition) (Allsop, 2009:92). Sometimes it is formed by two or sometimes three parts that contain a verb and an adverb or preposition. Most phrasal verbs are formed from a combination of a small number of the verb (go, get, sit, etc) and some number of particles (away, out, off, up, etc). Allsop (2009:93) said that Phrasal verbs occur in many idiomatic expressions, for example, sit down or get up.

Tournure idioms are the largest lexemic idioms, usually contain at least three words, and are mostly verbs. The tournure idiom brings metaphorical meaning, for example, to blow a fuse, means to get very angry.

The irreversible binomial idiom is a kind of idiom that has fixed structures which cannot be changed. It usually consists of two words, which are separated by a conjunction. For example, high and dry (without resources), Romeo and Juliet (institutionalized symbols of ideal love or symbol of true love), sink or swim (to either be successful right away or succumb to failure).

A phrasal compound idiom is a common form of idiom. Some words are combined into one, but its meaning is not based on its constituent elements. A phrasal compound idiom that contains primarily nominal made up of adjective plus noun, noun plus noun, verb plus noun, or adverb plus preposition. For example, blackmail (the 
payment force by intimidation), bookworm (a person committed to reading or studying), hot dog (food), white house (the Official Residence of the President of the United States).

Incorporating verbs idiom has spread in all-out daily activities even we do not realize it. It has also some forms such as noun-verb, adjective verb, and noun-adjective. This kind of idiom is mostly used in the formal term. For example, blood curding means to fill you with horror.

\section{The meanings of the idiomatic expressions}

The first thing to do is to understand all of the meaning of the source text. According to Chaer (2007:289) in his book Linguistic Umum is categorized into nine types of meaning that can be determined in the analysis of the meaning of the source. Namely:

Lexical Meaning is the smallest unit of meaning in the language meaning structure which could be differentiated from other similar units. Lexical meaning refers to the real meaning. The meaning that appropriates with the results of observation our sense of the meaning in the dictionary. For example, the lexeme 'horse' has the lexical meaning of four feet animal that usually we ride. And 'water' is a kind of liquid thing that is usually used in daily activities (Chaer, 2007:289).

Contextual meaning is the meaning of a lexeme or word inside a context (Chaer, 2007:290). The contextual meaning, however, could be considered to the situation where the time, the environment for language use, is used.

Grammatical meaning is the meaning that rises in a sentence as a result of word functioning. Grammatical meaning refers to the meaningful relationship between the constituent parts of the grammatical construction. This can be interpreted as a meaningful relationship between words, phrases, or sentences. Grammatical meaning presents if there was a process of grammatical in it as affixation, reduplication, composition, and syntactization (Chaer, 2007:290).

For example, the base word 'horse' produce grammatical meaning 'riding the horse'. Syntaxes process of word meaning 'young brother', kicking and ball; young brother is the 'subject', kicking means 'active', and the ball means 'object/target'. 
Conceptual meaning is the meaning that owned by a lexeme. It is free from context or association thing. Chaer (2007:293). stated that conceptual meaning can also be called a meaning that emphasizes logical meaning. For example, the word 'jasmine' has a conceptual meaning a kind of small flower, white, and fragrance flower, the word 'red' has a conceptual meaning a kind of bright color, and the word 'crocodile' that is conceptual meaning a kind of wild reptile which eats some animals, include carcass. So, the actual conceptual meaning is the same as the meaning of lexical, denotative, and referential.

Associative meaning is the meaning is owned by a lexeme or word related to that word relation with something outside of language. This associative meaning is the same with sign or symbolism that is used by a society of language used to explain another concept which has a resemblance with condition or characteristic from that origin word. For example, the word 'jasmine' is associated with something to holiness or purity, the word 'red' is associated with the braveness, and the word 'crocodile' is associated with the evil, bad, and crime. So, the associative meaning is the same as the meaning of connotative, stylistic, affective, and collocative (Leech: 1976:28).

A word is called referential meaning if that word has a reference. Referential meaning is the meaning that relates directly to the fact, or it can be called "dictionary meaning", such as horse, red, and images are included words of referential meaning because there are references in the real world. Instead of words such as and, or, and because is the words that are not meaningful referential, because the words do not have references (Chaer, 2007:291).

According to Chaer (2007:292) denotative meaning has similarities with lexical and conceptual meaning. Denotative meaning is the original meaning or the true meaning of a lexeme. A denotative identifies the central aspect of a word meaning based on something outside the language or based on certain conventions. For example, the word 'thin' is meant the body's condition of someone that smaller than normal size. The word 'flower' is meant denotative as a flower which we cultivate in the garden.

Connotative meaning is the figurative meaning or not a true meaning. Connotative meaning is also another meaning that is added in denotative meaning it is related to feeling from people or group who used that word. 
For example, the word 'flower', if it said "Dina is 'a flower' in our village", the meaning of a flower is not the same as the original meaning. The good character of that flower is imitated to Dina, and some people describe the beauty of Dina as a flower. So, the word 'thin' is a neutral connotation it's meant that has a good feeling. But, slim is the same as thin, it has a positive connotation, better than a thin and good feeling.

\section{METHOD}

The researcher used qualitative research and descriptive method that was suitable for the aim of the research. Te source of data on this research was Megamind movie, it was produced by Dream Works Animation, and distributed by Paramount Pictures. The film premiered on October 28, 2010, in Russia, while it was released in the United States in digital $3 D, I M A X 3 D$, and $2 D$ on November 5,2010 . The duration was 96 minutes. The technique of data collection used in this research is the documentation technique and the technique of data analysis used in the content analysis.

\section{FINDING \& DISCUSSION}

The phrasal verb is usually called a two-word verb of multiple verbs which consists of two or three words. Makkai (1972:135) mentions that phrasal idiom is a type of idiom in which the constituent is verb + adverb or preposition. These adverbs or prepositions are used after verbs are sometimes called adverbial particles, for example back, out, off, on, etc, for example:

a) on your weak willed mind to find out all our secrets.

In this picture, the writer analyzes the underlined word which is classified as an idiom verb phrase. This can be analyzed from the find out sentence uttered by the Megamind character. In this sentence some sentences contain idioms, the word find is a verb which means to find, especially where something or someone is, either unexpectedly or by searching, or to find where to get or how to achieve something, and the word out is an adverb word, a preposition which means it is used to indicate movement away from the inside of a place or container, so the word find out has the meaning of knowing something hidden.

\section{Tournure Idiom}


A tournure idiom is a verb phrase idiom which contains at least three lexicons or words and containing the definite article or indefinite article. The tournure idiom brings metaphorical meaning (Makkai, 1972:148), for example:

b) Even fate picks its favorites.

In this picture, the author analyzed the underlined words classified as tournure idioms. This can be analyzed from the sentence even fate picks its favorites uttered by the character Megamind. In this sentence, there is a sentence that contains idiom meaning, the sentence Even fate picks its favorite contains idioms in which there are verbs and articles, namely words that have no meaning but describe a noun. The meaning of the sentence is to choose the conditions according to your wishes.

\section{Phrasal Compound Idiom}

Makkai (1972:164) also said that phrasal compound idiom is a common form of idiom. Some words are combined into one, but its meaning is not based on its constituent elements. This kind contains primary nominal which pattern can be adjective + noun, noun + noun, and verb + noun, for example:

c) although getting a whole museum is super cool.

In this picture, the writer of the underlined word is classified as an idiom compound phrase. These can be sentences from the entire museum uttered by Metroman figures. In this sentence there are sentences that contain idioms, the sentence whole museum is super cool contains meaning idioms consisting of adjectives and nouns, the words whole and cool are adjectives, and the words museum and super are nouns which mean a very exhibition place interesting.

\section{Incorporating Verbs Idiom}


Incorporating verb idioms is a kind of idiom in which the first element is either a noun or an adjective which is attached to the verb (Makkai, 1972:168), for example:

d) It's 'revenge' and it's best served cold.

In this picture, the writer analyzes the underlined word which is classified as Incorporating Verbs Idiom. This can be analyzed from the best served sentence uttered by the Metroman character. The sentence best served contains idiomatic meanings consisting of adjectives and verbs, best is an adjectives, and served is verbs which mean to serve the needs of others well.

\section{Meaning Of The Idiomatic Expression}

\section{Lexical Meaning}

a) Oh, you know boys are. They love video games.

In the picture, it is told that the Minion is suggesting to Megamind that he should change his Titan teaching technique, because Titan is the son of a boy who usually only likes to play games, not to learn, and at the same time Megamind receives a notification on his cellphone that contains a reminder of the meeting between himself (Megamind) and a beautiful reporter named Roxanne, before getting a notification, Minion and Megamind train Titan to become a superhero who aim to fight himself, namely Megamind, then Megamind is injured as a result of disguising himself as a "space father" who training Titan to fly.

The meaning of the word in the sentence is the lexical meaning. The sentence is spoken when the Minion is with Megamind in a secret room which means a boy who mostly has a hobby of playing games, video games are games that interact with the user, the user interface through the image generated by the video device. The sentence shows a lexical meaning because in the sentence there are words that contain symbols of objects, namely video games.

\section{Contextual Meaning}




\section{Character Megamind}

a) or this will be the last you ever hear of.

In the picture, the Megamind is messing with the museum opening. Megamind and his sidekick named Minion are at the observatory, they kidnap Roxanne Ritchie, they kidnap a reporter who used to lure Metroman to come to her observatory and destroy Metroman. From a distance the Megamind talks to the Metroman using a big screen, in the middle of the museum opening which is witnessed by all residents of the metro city, the Megamind threatens the Metroman.

The meaning of the word in the sentence is contextual meaning. This can be analyzed from the sentence uttered by the Megamind character, the sentence is said when Megamind and the Minion kidnap a woman, Megamind warns Metroman that maybe the life of someone they kidnapped will end soon, or Metroman will not be able to hear Roxanne's voice again. This sentence shows contextual meaning because in this sentence there is a threat uttered by Megamind, namely in the sentence the last you ever hear of.

\section{Dominant Idiomatic Expression}

\section{Graph 4.1}

Idiomatic Type of Expression

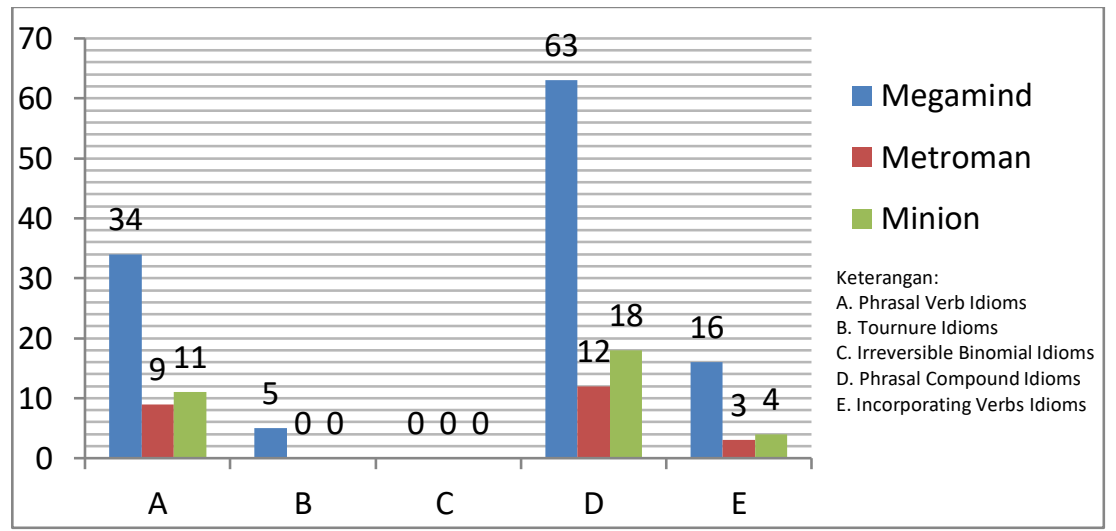


Based on this graph, it can be seen that the most dominant types of idiomatic expressions used by the characters in the Megamind movie are found in the main character in the movie, namely the Megamind character, there are as many as 63 types of Phrasal Compound Idioms and as many as 33 types of Phrasal Verb Idioms.

\section{CONCLUSIONS (خلاصة |خاتمة)}

There are 4 types of idiom expressions used by characters in the Megamind movie, namely the first type of Phrasal Verb Idiom, 54 idioms are consisting of 34 idioms found in Megamind characters, 9 idioms found in Metroman character, and 11 idioms contained in Minion character, the second is Tournure Idiom, there are 5 idioms found in Megamind character, the third types of Phrasal Compound Idioms, there are 93 idioms found, 63 idioms found in Megamind character, 12 idioms contained in Metroman character, and 18 idioms contained in Minion character, and the fourth type of Incorporating Verbs Idioms found 23 idioms, 16 idioms on Megamind character, 3 idioms on Metroman character, and 4 idioms on Minion character. In analyzing the meaning of idiomatic expressions used by the characters in the Megamind movie, the writer defines these expressions based on the utterances spoken by the characters and based on the impressions in the movie. In the Irreversible Binomial idiom type, the researcher did not find a single character in the Megamind movie character who used this type of idiom.

\section{BIBILIOGRAPHY (قائمة المراجع)}

\section{References :}

Allsop, Jake. 2009. Test Your Phrasal Verb. Edinburg: Pearson Education Limited.

Baker, Mona. 1992. In Other Words: A Course Book on Translation. London: Routledge.

Chaer, Abdul. 2007. Linguistik Umum. Jakarta: PT. Rineka Cipta.

Hinkel, Eli. Teaching Idiomatic Expressions and Phrases: Insight and Techniques. Iranian Journal of Language Teaching Research. October. 2017. Vol. 5. No. 3. K, Mantyla.2004. Idioms and Language Users: The Effect of the Characteristic of idioms on their Recognition and Interpretation by Native and Non-Native Speaker of English. Thesis. Unpublished. University of Jyvaskyla Press. 
Keraf, Gorys. 1984. Diksi dan Gaya Bahasa. Jakarta: Gramedia Pustaka Utama. Leech, Geoffrey. 1976. Semantik 1 dan 2. Utrecht Antwerp: Uitgevery Het Spectrum. Makkai, Adam. 1972. Idiom Structure in English. Paris: The Hague. Mouton. 